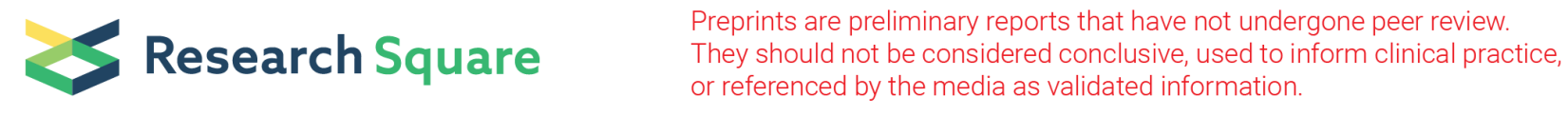

\title{
Monitoring Land Subsidence With The Combination of Persistent Scatterer Interferometry Techniques And Distributed Fiber Optic Sensing Techniques: A Case Study In Suzhou, China
}

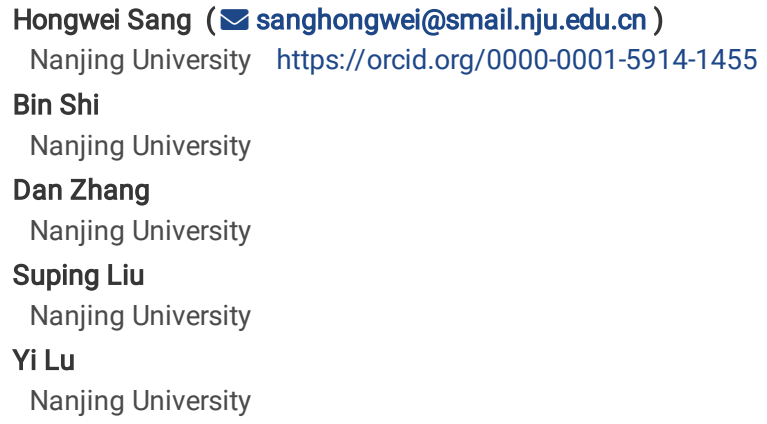




\section{Abstract}

Land subsidence is a global geo-hazard caused by various natural and human factors, and it directly threatens the safety of the environment and infrastructures. Investigating the mechanism of land subsidence is becoming more and more important. In this paper, we use the Persistent Scatterer Interferometry (PSI) technique combining the Distributed Fiber Optic Sensing (DFOS) technique to detect the spatial-temporal distributions of land subsidence and investigate the stratum deformation characteristics in Shengze, Suzhou. By analyzing Sentinel-1A date between 2017 and 2019 with the PSI technique and the deformation date derived by the DFOS technique, we conclude that the land surface deformations are mostly affected by the transitional exploitation of groundwater. The average Line-Of-Sight (LOS) deformation rate is mostly concentrated in -3 to $2.2 \mathrm{~mm} / \mathrm{yr}$, and a maximum subsidence rate of up to -16.9 $\mathrm{mm} / \mathrm{yr}$ is observed in four industrial areas. Meanwhile, the DFOS-derived results reveal that the compression strata are mostly concentrated in $41.2-137.9 \mathrm{~m}$ depth, which is closely associated with the pore water pressure in the second confined aquifer. And it also reveals that the groundwater over-exploitation may be the significant triggering factor of the subsidence in the study area. The InSAR-derived results are also evaluated by the deformation time series obtained by the DFOS technique. The combination of those two new sensing and monitoring technologies enables us to highlight the large deformation area and reveal the mechanism of its subsidence, which is conducive to urban development, disaster risk management, and rational exploitation and management of groundwater in Suzhou.

\section{Highlights}

- The spatial-temporal distributions of subsidence were detected by the PSI method.

- Strain distribution can be used to reflect the stratum deformation characteristics.

- Two sensing technologies were adopt to amply reveal the mechanism of subsidence.

\section{Introduction}

Land subsidence has been a normal problem in many areas of the world, such as Italy (Del Soldato et al. 2018), Mexico (Osmanoğlu et al. 2011; Yan et al. 2012), Iran (Goorabi et al. 2018; Khorrami et al. 2020), Thailand (Phien-Wej et al. 2006), American (Loesch et al. 2018; Miller et al. 2019), China (Wang et al. 2020; Yu et al. 2020), and so on. And it has a significant impact on social and economic development, due to its damages to urban infrastructure including buildings, railways, highways, subways, and underground facilities (Dong et al. 2014). Thus, land subsidence investigations are essential to figure out the spatial of the affected areas, and the mechanism of land subsidence.

Traditionally, land subsidence is usually monitored by the leveling, total station surveys, and GPS field surveys. However, all these are ground-based measurements at sparse locations, and they cannot achieve a sufficiently high spatial density over large areas. Over the last two decades, Synthetic Aperture Radar Interferometric (InSAR) has proven a remarkable potential tool for observing the Earth's surface (Galloway et al. 1998; Hoffmann et al. 2001; Hooper et al. 2008; Becker et al. 2009). Meanwhile, to overcome the effects of temporal and spatial decorrelation and atmospheric perturbations, advanced InSAR techniques have been developed recently. And the PS-InSAR method has been widely applied in monitoring the subsidence in the urban area (Sun et al. 2017; Zhang et al. 2011; Gido et al. 2020). By measuring phase changes between different images acquired at different times but with the same geometry of observation (so-called interferograms), the deformations in land surface can be measured (Ferretti et al. 2001, 2007; Cian et al. 2019). And the surface displacement with centimetric accuracy, tens meters of spatial resolution, and monthly temporal resolution can be resolved (Xiao et al. 2011).

It is worth noting that the time series of subsidence obtained by the InSAR method are always comparing with the GNSS, leveling, and so on (Hung et al. 2018; Poland et al. 2006; Chen et al. 2017). Although this combination can well verify the monitoring accuracy of subsidence among each other, it is just representing the surface deformation, and the mechanism of land subsidence cannot be fully disclosed. To better understand the mechanism of subsidence, it is critical to measure the compaction of the soils at different depths. Meanwhile, the Distributed Fiber Optic Sensing (DFOS) technology has been successfully applied to many kinds of structural health monitoring, such as tunnels, bridges, concrete piles, rock slope, etc (Li et al. 2004; Zhu et al. 2014; Sang et al. 2019). It has many unique functions, such as non-destructive capability in distributed monitoring and long-distance monitoring, anti-electromagnetic interference, waterproof, corrosion resistance, durability, etc (Wu et al. 2021). To this end, the deep strata deformation characterization can also be investigated detailedly by using the DFOS techniques in the subsidence monitoring (Liu et al. 2020). Meanwhile, combining with the PS-InSAR technique, the mechanism of land subsidence in a certain area can be fully exposed. And it is of great significance to urban planning and management.

In this study, the spatial distribution of the ground surface deformation in Suzhou is investigated by the Persistent Scatterer Interferometry (PSI) technique. The PSI technique can be used to map the location of hazard zones and their ongoing subsidence rate. Meanwhile, the DFOS technique can be used to get the strain distribution of the fiber optical cable in the borehole, which is helpful to pinpoint the main compression layers, determine the compression trends, and allow estimation of land subsidence potential. Combining the two techniques, it can be used to define the risk zones for future ground subsidence and to establish a comprehensive ground survey plan with information on rapidly subsiding areas, detailed time-series deformation and the strata deformation characterization at each borehole. Meanwhile, given the ground subsidence caused by the exploitation of groundwater, it will also provide a practical basis for the rational exploitation and management of groundwater.

The paper is organized as follows: Sect. 2 (Study area) displays the overview of the region; Sect. 3 (Materials and Methods) describes the data used and the methodology employed for the analysis; Sect. 4 (Results and Discussion) presents the results obtained by the two methods and discusses the findings; Sect. 5 (Conclusions) concludes.

\section{Study Area}


In this paper, the study area is mainly located in the southeastern of Suzhou, southeastern Jiangsu, China. It is part of the Su-Xi-Chang area including Suzhou, Wuxi and Changzhou. It is also located in the lower Yangtze River alluvial plain, which is on the south of the Yangtze River and the north of TaiHu Lake, as illustrated in Fig. 1. In this region, the average elevation is less than $6 \mathrm{~m}$ above sea level. The Quaternary strata are widely distributed, but their hydrodynamic conditions and the formation types are very complex, as illustrated in Fig. 2 and Fig. 3.

According to statistics, this area suffered from severe ground subsidence caused by extensive groundwater exploitation in the past several decades (Wu et al. 2008; Shi et al. 2012). Meanwhile, the restrictions on groundwater exploitation (RGE) have been imposed by the government since 1997 to prevent further elevation loss. And the spatial-temporal ground deformation response to the RGE policy has been characterized by using the multiple InSAR method whose results suggest that urban subsidence in Suzhou was under control by 2006 (Shi et al. 2021). Although the RGE policy has been carried out, the considerable pumping continued and varied in different counties. Currently, the ground subsidence rate in the Shengze town is one of the largest at the Wujiang distinct of Suzhou. In the meantime, the subsidence has some characteristics of aggregation distribution which is urgent to analyze the mechanism of subsidence. Therefore, it is of great importance to figure out the characterization of deep deformation and the distribution of land surface subsidence.

\subsection{Stratigraphic feature}

Land subsidence is closely related to the stratigraphic feature and the hydrogeological conditions. Therefore, to explore the deformation characteristics of subsurface strata, a borehole (Labeled SZ in Fig. 1) with $200 \mathrm{~m}$ depth and $129 \mathrm{~mm}$ diameter was drilled within the campus of Shengze Middle School (30 53' $23.96^{\prime \prime} \mathrm{N}, 120^{\circ} 40^{\prime} 47.11^{\prime \prime} \mathrm{E}$. And the detailed lithology and aquifer system classification in the Shengze borehole is shown in Fig. 2 . It can be seen that the hydrogeological conditions in the area are complicated. And the complex aquifer-aquitard system consists of intercalated sands, silts, silty clays, and clays, which can be divided into the shallow soil filling (Qml), three confined aquifers (Af1, Af2, and Af3), and four aquitards (Ad1, Ad2, Ad3, and S-s). And the confined aquifers (Af1, Af2, and Af3) are composed of sands as the major constituents and little silts. The aquitards are consist of silty clays and clays as the main component.

Simultaneously, there are some boreholes in the three sites located in the Pingwang Town, Sian Bridge and the Shengze Middle School, as shown in Fig. 3(a). Based on the survey sites in the study area, the hydrogeological profile along the $\varangle-\varangle^{\prime}$ section is also plotted, as shown in Fig. 3(b). It can be seen that the distribution of groundwater aquifers is relatively consistent in the study area. Also, the types and depth distribution of soil layers are relatively uniform in the study area. Hence, it can be concluded that the law of the subsidence in this area has a high consistency.

\section{Methods And Materials}

\subsection{Persistent Scatterer Interferometry (PSI) technique for land subsidence monitoring}

In this paper, a set of 35 Sentinel-1A data is acquired from the European Space Agency, and which is used to investigate subsidence in the lower Yangtze River alluvial plain by the Persistent Scatter Interferometry (PSI). This work has been carried out using the open-source ESA SNAP and StaMPS software packages (Grassi et al. 2019). By using the PS-InSAR technique, the detection of displacements at the typical level of accuracy (mm/yr) can be achieved.

Our area of interest (AOI) and the extent of Sentinel-1 ascending (A171) orbits are illustrated in Fig. 1. The set of selected data covers from January 2017 to December 2019, and the data is collected once a month. And the detail information can be obtained from the tables and charts below. Table 1 shows some details on the Sentinel-1A data employed for the processing. And Table 2 details the parameters involved in master image splitting for burst selection over the AOI. Meanwhile, Fig. 4 displayed the spatial and temporal baseline configuration of Sentinel-1A (Track 171) interferometric pairs.

Table 1

Sentinel-1 data employed for processing, with first and last image of each dataset, orbit pass, track and number of acquisitions

\begin{tabular}{|llllll|}
\hline Satellite & First Image & Last Image & Orbit Pass & Track & N Acquisitions \\
\hline S1A & $2017 / 01 / 22$ & $2019 / 12 / 02$ & Ascending & 171 & 35 \\
\hline \multicolumn{5}{c}{ Table 2}
\end{tabular}

Main characteristics of the selected Sentinel-1A master scene

\begin{tabular}{|llllll|}
\hline Track & Acquisition Date & Sub-Swath & Polarization & Initial Burst & Last Burst \\
\hline 171 & $2018 / 05 / 05$ & IW1 & VV & 6 & 7 \\
\hline
\end{tabular}

\subsection{Distributed fiber optic sensing techniques for land subsidence monitoring}

The DFOS techniuqe has been widely used in the monitoring of the land subsidence (Gu et al. 2018; Wu et al. 2021). In this paper, Brillouin optical time-domain refractometer (BOTDR) and fiber Bragg grating (FBG) are adopted to get the strain date of the cable and the pore water pressure in the aquifer layer.

Figure 5 illustrates the general monitoring scheme of land subsidence based on the DFOS technique. After the borehole was drilled to bedrock, the sensing cables were dragged down to the bottom by attaching a heavy guider which could also keep cables tight during installation. Then, the borehole was back-filled with a mixture of gravel, sand, and clay. When the back-filled material was compacted to stability, the initial strain of the embedded cables can start to be recorded. The strain sensing cable is connected to the BOTDR demodulator for monitoring full-distributed strain, and the FBG osmometer was deployed at the bottom of the second aquifer ( $87.7 \mathrm{~m}$ deep), which is used to monitor pore fluid pressures by connecting to the FBG demodulator. Meanwhile, Fig. 5(a) shows that there are some fixed points in the strain sensing cable. And the interval between adjunct fixed points is $10 \mathrm{~m}$ that is specially designed for detecting 
accurate deformation in detail. And Fig. 5(b) illustrates the cross-section of the strain sensing cable, whose diameter is about 5 mm. Afterward, the FBG osmometer is shown in Fig. 5(c).

The initial strain distributions on the strain sensing cable in SZ were recorded on December 25, 2012. And the data acquisition interval was about $1-3$ months by the DFOS technique. In this paper, the data of the strain distributions acquired from December 27, 2016 to November 23, 2019 are used for analysis. And the strain distributions recorded on December 27, 2016 is recognized as initial data. Then, after subtracting the initial strain date, the processed data (as shown in Fig. 9) can be used to calculate the soil deformation in different layers.

\section{Results And Discussion}

\subsection{Spatial-temporal distribution of subsidence}

Figure 6 exhibits the Sentinel-1A average Line-Of-Sight (LOS) deformation rate maps over the period January 2017 - December 2019 . The negative value represents the amount of motion away from the satellite, and the positive value represents the amount of motion toward the satellite. The deformation rate maps mainly coverages the Wujiang District of Suzhou City, the Xiuzhou District of Jiaxing City, and the Jiashan District of Jiaxing City. And the obtained PS density is about $2415 \mathrm{PSs} / \mathrm{km}^{2}$ in the study area. It can be seen that the LOS deformation rate in this area is mostly distributed between -3 and $2.2 \mathrm{~mm} / \mathrm{yr}$, which means this region is relatively stable. But there are still four subsidence bowls mainly located in the southeastern of the Wujiang District, as shown in areas $A, B, C$, and $D$. And the largest deformation rate is almost $-16.9 \mathrm{~mm} / \mathrm{yr}$.

From Fig. 6, it can be seen that the interfere-metric analysis shows a surface displacement ranging from - 16.9 to $2.2 \mathrm{~mm} / \mathrm{yr}$ in the LOS direction. Meanwhile, the $\mathrm{I}-\mathrm{I}$ ' cross-section is trending north-south with a smooth change in the subsidence rate between the maximum and minimum values. Along the north-south direction, the subsidence rate gradually increased towards the center of the subsidence bowls. And at the edge of the subsidence bowl, the measured subsidence rate was about $-10 \mathrm{~mm} / \mathrm{yr}$.

\subsubsection{Subsidence of large-scale man-made linear features}

Figure 7 shows the spatial distribution characteristics of the subsidence area A, B, C, and D on the Google image. It can be seen that the subsidence area (where the average LOS deformation rate is from - 11 to $-16.9 \mathrm{~mm} / \mathrm{yr}$ ) is mostly concentrated near the large factory area, where has a large amount of groundwater exploitation. And it can be inferred that the subsidence of this area is mainly caused by the man-made excessive exploitation of groundwater.

In addition, the PSI LOS average displacement time series in areas A, B, C, D were obtained. Figure 8 shows the time series of average LOS displacements within a $100 \mathrm{~m}$ radius near the center of the four subsidence areas. The displacement time series curve is fitted by the piece-wise linear method, as shown in the red solid line. And the a1, a2, a3, a4, a5, and a6 are the slope value of the fitting lines, which can reflect the rate of subsidence. The larger the value of the slope is, the smaller the rate of subsidence is. It can be obvious that a1 >a2, a3 > a4, and a5 > a6. In areas B, C, and D, the same pattern can also be seen. Under appeal information, it can be concluded that the deformation is significantly accelerated from June/July to November/December every year, after which the subsidence rate begins to slow down. And it will even produce the spring-back phenomenon. It can be inferred that the subsidence of this area is mainly controlled by the seasonal man-made groundwater extraction. By using the PS-InSAR method, the subsidence area with large-scale man-made linear features can be easily detected, which is of great importance to help the government effectively plan and manage the exploitation of the groundwater in the city and avoid unnecessary economic losses.

\subsection{Stratum deformation characterization}

Figure 9 shows the strain distribution of the strain sensing cable in the borehole SZ after subtracting the initial strain date. It can be seen that abnormal strain values are registered at a depth of 0-6 $\mathrm{m}$ which could be due to the variation of shallow soil temperature or soil disturbance (Kogure and Okuda 2018). And the width of peak and valley could be limited in a readout interval of $0.05 \mathrm{~m}$ by the DFOS interrogator used for short-term detection with a high spatial resolution of $0.05 \mathrm{~m}$. It can be easily found the dominant contributors to the land subsidence. It can be seen that the negative strain values are mainly distributed in the Ad2 and Ad3 (41.2-137.9 m depth). In the borehole SZ, the soil layer is easily compressed under groundwater withdrawal, because of the structure characteristic of the alternating clayey soil layer and loose sand layer. When groundwater is pumped from the aquifer, the pore water pressure reduces; Then, the effective stress of the soil decreases; Hence, the underlying soil will be compacted and settled by the extrusion of the upper soil layer. Meanwhile, it should be noted that there are some positive strain peaks at the junction of the aquitard and the aquifer, as shown by the solid black arrow. And there are also some positive strain peaks at the aquitard, as shown by the dotted black arrow. It can be caused by the shear interaction between the clay soil layer and the sand layer. In conclusion, most peaks locate in the Ad2 and Ad3, which are adjacent to Af2. It infers that the hydraulic activity is relatively active in this depth, which also illustrates the subsidence is almost controlled by the Af2.

\subsubsection{Distribution and Characteristics of Soil Deformation}

In Sect. 4.1.1, the severe subsidence area has been investigated, and whose mechanism is also considered as the seasonal man-made groundwater extraction. While the deep deformation characteristic is still not clear. Therefore, the DFOS technique is used to explore the stratum deformation characteristic in the borehole SZ (where the LOS deformation rate is relatively small).

It is well known that the subsidence is controlled by the compression amount in different soils. In Sect. 4.2, the deformation characteristics of deep strata are only qualitatively analyzed. While taking advantage of the strain distribution of the cable in the borehole, the deformation of the deep stratum can be 
detailedly reflected. According to the processed strain data, the values of soil deformation at different layers can be obtained. It should also be noted that strain data at shallow depth $(<15 \mathrm{~m})$ was not adopted here due to the weak coupling of cable and soil within this depth (Zhang et al. 2020).

Meanwhile, comparing with the largest subsidence derived from the InSAR technique in each year, the main compressed layer can be detected and the characteristic of different soil can also be reflected easily. According to the strain distribution of the cables and the InSAR-derived results, the maximum settlement between March and December in each year in different soil layers is illustrated in Table 3 . In Table 3 , the K can represent the compression capacity of soil. It can be seen that the compression capacity of soil in Af2 is the largest and Ad2 is the next. And the DFOS/InSAR in the Table 3 can also reflect the percentage of different soil layers in the total subsidence. The soil layers in Ad2, Af2 and Ad3 may be the main compressed layers, whose compression amount accounts for $60 \%$ of the total compression amount. From the time scale, the subsidence of the soil in Af3, Ad4 and S-s is decreasing year by year and the deep soil tends to be consolidated and hardened. While the soils in Af2 still have high compressibility, which can be verified by the value of the subsidence from 2017 to 2018. It can be concluded that the compressive deformation of the sand layer in Af2 and the cohesive soil in Ad2 and Ad3 closely related to the hydraulic power of Af2 is the largest at the present stage, and it will continue to develop for a period of time.

Hence, in the absence of other known tectonic and geological processes, and based on the above correlations, we believe that the land subsidence phenomenon in the study area is mainly triggered by the over-exploitation of the Af2.

Table 3

The distribution of the maximum subsidence in different soil layers

\begin{tabular}{|c|c|c|c|c|c|c|c|c|c|c|c|}
\hline \multirow{2}{*}{$\begin{array}{l}\text { Aquifer } \\
\text { groups }\end{array}$} & \multirow{2}{*}{$\begin{array}{l}\text { Main } \\
\text { Soil- } \\
\text { type }\end{array}$} & \multirow{2}{*}{$\begin{array}{l}\text { Depth } \\
\text { (m) }\end{array}$} & \multirow{2}{*}{$\begin{array}{l}\text { Thickness } \\
\text { (m) }\end{array}$} & \multicolumn{2}{|c|}{$\begin{array}{l}\text { Subsidence in } \\
2017(\mathrm{~mm})\end{array}$} & \multirow{2}{*}{$\begin{array}{l}\text { DFOS/ } \\
\text { InSAR } \\
(\%)\end{array}$} & \multirow{2}{*}{$\begin{array}{l}\text { K } \\
\text { (Subsidence/Thickness) }\end{array}$} & \multicolumn{2}{|c|}{$\begin{array}{l}\text { Subsidence in } \\
2018(\mathrm{~mm})\end{array}$} & \multirow{2}{*}{$\begin{array}{l}\text { DFOS/ } \\
\text { InSAR } \\
(\%)\end{array}$} & \multirow{2}{*}{$\begin{array}{l}\text { K } \\
\text { (Subsidence/Thickness) }\end{array}$} \\
\hline & & & & DFOS & InSAR & & & DFOS & InSAR & & \\
\hline Ad1 & clay & $15-37$ & 22 & 0.770 & \multirow[t]{8}{*}{11.180} & 6.89 & 0.035 & 0.249 & \multirow[t]{8}{*}{7.368} & 3.38 & 0.011 \\
\hline Af1 & sand & $\begin{array}{l}37- \\
41.2\end{array}$ & 4.2 & 0.153 & & 1.37 & 0.036 & 0.135 & & 1.83 & 0.032 \\
\hline Ad2 & clay & $\begin{array}{l}41.2- \\
74.35\end{array}$ & 33.15 & 3.182 & & 28.46 & 0.091 & 1.938 & & 26.30 & 0.058 \\
\hline Af2 & sand & $\begin{array}{l}74.35- \\
87.7\end{array}$ & 13.35 & 1.351 & & 12.08 & 0.101 & 1.635 & & 22.19 & 0.122 \\
\hline Ad3 & clay & $\begin{array}{l}87.7- \\
137.9\end{array}$ & 50.2 & 2.237 & & 20.01 & 0.045 & 1.076 & & 14.60 & 0.021 \\
\hline Af3 & sand & $\begin{array}{l}137.9- \\
151\end{array}$ & 13.1 & 0.576 & & 5.15 & 0.044 & 0.120 & & 1.63 & 0.009 \\
\hline Ad4 & sand & $\begin{array}{l}151- \\
165.1\end{array}$ & 14.1 & 0.391 & & 3.50 & 0.028 & 0.223 & & 3.03 & 0.016 \\
\hline S-S & sand & $\begin{array}{l}165.1- \\
200\end{array}$ & 34.9 & 0.827 & & 7.40 & 0.024 & 0.216 & & 2.93 & 0.006 \\
\hline
\end{tabular}

\subsubsection{Subsidence of stable fluctuation characteristics}

Figure 10 shows the deformation in the different depth ranges (from 15 to $200 \mathrm{~m}$ depth) along the borehole SZ and the variation of the pore water pressure in Af2. By the comparison of the deformation in different depths, it is obvious that the value of the deformation from 41.2 to $137.9 \mathrm{~m}$ depth (where consists of Ad2, Af2 and Ad3) is the largest; while the value from 15 to $41.2 \mathrm{~m}$ depth and 137.9 to $200 \mathrm{~m}$ depth are around zero. Again, it has proved that the subsidence around the borehole SZ is mainly controlled by the Ad2, Af2, and Ad3.

At the same time, it can be seen that the deformation from 41.2 to $137.9 \mathrm{~m}$ depth has a certain fluctuation in Fig. 10. The maximum fluctuation value of deformation value is around $9 \mathrm{~mm}$, and the value decreases year by year. The average deformation rate is between $-1-1 \mathrm{~mm} / \mathrm{yr}$ in the three years, which also reveals that this region around the borehole SZ is relatively stable. To clearly understand the above wave deformation law, we also compared the distribution of pore water pressure in the deep soil layer with the distribution of the deformation. From Fig. 10, the variation of the pore water pressure has a good consistency with the deformation from 41.2 to $137.9 \mathrm{~m}$ depth, which indicated that the subsidence rate generally increased or decreased along with the decline or rise of the groundwater level, respectively. This also indicates that the subsidence in this region is mainly impacted by groundwater fluctuations near the Af2.

\subsection{Comparison and analysis}

By comparing Fig. 8 and Fig. 10, it can be obtained that the significant acceleration of subsidence occurs mostly in the middle of each year. In Fig. 8 , the average LOS displacements are significantly accelerated from June/July every year. Meanwhile, the time points of acceleration of deformation in 41.2-137.9 $\mathrm{m}$ depth are about from May/June in Fig. 10. This consistency indirectly verified the accuracy of the PSI-derived results. Of course, there is a little difference in the located region between Fig. 8 and Fig. 10. There is a certain distance between the study areas in the two figures. But the strati-graphic characteristics in the overall study area are coincident, which can be seen from Fig. 2 and Fig. 3. And the distance is also a small problem that can be ignored. It also indirectly proves that the subsidence is mainly affected by the groundwater withdrawal in the study area. 
Next, the time series of average LOS displacements within $100 \mathrm{~m}$ radius near the center of the borehole SZ is compared with the deformation on 41.2 to 137.9 $\mathrm{m}$ depth obtained by the DFOS technique, as shown in Fig. 11 and Fig. 12. To be sure, the LOS displacement reflects the displacement between the satellite and the ground. And the vertical displacement can be calculated by the following:

$D_{v}=D_{\text {Los }} / \cos (\theta)$

Where $D_{v}$ is the vertical displacement obtained by the PSI method; $D_{\text {LOS }}$ is the LOS displacement received by the PSI method; $\theta$ is the incidence Angle between the satellite and the ground. In addition, the satellite has a smaller incidence Angle to the earth's surface. Therefore, the LOS displacement can be used for replacing the vertical displacement in this paper. Meanwhile, the deformation obtained by the DFOS technique mainly occurs in the $41.2-137.9 \mathrm{~m}$ depth. The deformation from 41.2 to $137.9 \mathrm{~m}$ depth can represent the overall deformation characteristics. To this end, this comparison can be a good example of the InSAR-derived results, which can also demonstrate the mechanism of land subsidence well in a regional area.

From Fig. 11, it can be seen that the LOS deformation points measured by the PS-InSAR technique are distributed around the curve of the deformation on 41.2 to $137.9 \mathrm{~m}$ depth obtained by the DFOS. Simultaneously, the deformation on 41.2 to $137.9 \mathrm{~m}$ depth obtained by the DFOS can be used to reflect the overall subsidence laws. Therefore, the InSAR-derived results are well verified by the DFOS-derived results. It should also be noted that the area is still affected by water level fluctuations caused by groundwater extraction, although the overall region is relatively stable.

Figure 12(a) shows the distribution of the deformation rate obtained by the PSI near the borehole SZ. The deformation rate is between - 3 and $2.2 \mathrm{~mm} / \mathrm{yr}$ near the borehole SZ, which also reveals that the region is relatively stable. And Fig. 12(b) shows the time series of the LOS deformation in P1, P2, and P3 near the borehole SZ. And the LOS deformation points are also distributed around the curve of the deformation at 41.2-137.9 $\mathrm{m}$ depth, and the overall law is consistent. Consequently, the accuracy of the InSAR-derived results is verified by the DFOS-derived results. For the above description, we concluded that the subsidence is mostly affected by the Af2 in the study area.

\section{Conclusion}

In this paper, land subsidence was easily detected by the PSI method and the DFOS technique. A case study in Suzhou was examined. Taking advantage of both of these techniques, not only the spatial-temporal distribution of subsidence can be received, but also the detailed subsurface deformation characters can be offered. Meanwhile, the accuracy of the PSI-derived results was adequately verified by the DFOS-derived results. The following conclusions can be drawn:

(1) The LOS deformation rate obtained by the PSI method in Shengze reflects the overall distribution of the land surface subsidence. And the LOS deformation rate is ranging from - 16.9 to $2.2 \mathrm{~mm} / \mathrm{yr}$ between 2017 and 2019 in the study area. There are four subsidence bowls located in the southwestern of the Wujiang District in Suzhou, where the subsidence rate is ranging from - 11 to $16.9 \mathrm{~mm} / \mathrm{yr}$. Moreover, the LOS deformation rate is mostly concentrated in -3 to $2.2 \mathrm{~mm} / \mathrm{yr}$ in the study area, which also reveals that this region is relatively stable in the 3 years.

(2) By analyzing the distribution of the LOS deformation rate between -16.9 and $-11 \mathrm{~mm} / \mathrm{yr}$, it can be seen that the subsidence bowls are mostly distributed in the large factory regions. The subsidence in this region has a large-scale man-made linear feature. Meanwhile, not only in the severe subsidence area but also in the relatively stable area (near the borehole SZ), the subsidence accelerating time points both occurred in the middle of each year. According to the deep deformation results obtained by the DFOS technique and the InSAR-derived results, it can be found that the subsidence has a fluctuation characteristic, which is closely related to the variation of the groundwater level in the aquifer Af2. Therefore, it can be concluded that the subsidence is mostly related to the groundwater level, which is mostly affected by the seasonal excessive exploitation of groundwater in the study area.

(3) The DFOS technique offers new insight into subsurface deformation, the deformation of different soil layers can be showcased directly. In the study area, the sand layers in Af2 have high compressibility than orthers. And the clay layers soils near Af2 are also suffering greater compaction. Meanwhile, comparing with the overall subsidence amount derived from the PS-InSAR technique, it is ascertained that the main compression zone is located at a depth of $41.2-137.9$ $\mathrm{m}$, where it contains two aquitards Ad2 and Ad3 adjacent to aquifer Af2. It can also be concluded that the subsidence is mainly affected by the overexploitation in the pumping aquifer Af2 in the study area.

(4) The accuracy of the InSAR-derived results is verified by the DFOS-derived results for the first time in this paper. And the deep stratum deformation characteristics are also amply investigated, which is of great importance for revealing the mechanism of the subsidence. According to the results derived from the two methods, it can be concluded that the major cause of land subsidence in the study area is the man-made over-pumping groundwater. Also, the combination of those two techniques is beneficial to disaster risk management and urban development, which also provides a base for drawing up a proper management scheme of groundwater resources and a good case for analyzing the subsidence caused by the over-exploitation.

\section{Declarations}

\section{Acknowledgments}

This work was supported by the National Natural Science Foundation of China grants (42030701 and 41427801$)$, and Postgraduate Research \& Practice Innovation Program of Jiangsu Province grant (KYCX19_0048). We would like to thank Jian-Hui He and Song-Ge Shi from Nanjing University, Guang-Qing Wei from Suzhou NanZee Sensing Technology Ltd., and all those people who were involved in the land subsidence monitoring in Suzhou for their field and technical assistance.

Credit Author Statement

Page 6/15 
Hong-Wei Sang: Conceptualization, Methodology, Writing - Original Draft, Writing - Review \& Editing

Bin Shi: Writing - Original Draft, Supervision, Funding acquisition

Dan Zhang: Writing - Review \& Editing, Formal analysis

Su-Ping Liu: Writing - Review \& Editing

Yi Lu: Investigation

\section{Declaration of interests}

The authors declare that they have no known competing financial interests or personal relationships that could have appeared to influence the work reported in this paper.

QThe authors declare the following financial interests/personal relationships which may be considered as potential competing interests:

\section{References}

1. Becker, R. H., Sultan, M., 2009. Land subsidence in the Nile delta: inferences from radar interferometry. Holocene. 19(6), 949-954. https://doi.org/10.1177/0959683609336558

2. Cian, F., Blasco, J. M. D., Carrera, L., 2019. Sentinel-1 for monitoring land subsidence of coastal cities in Africa using PSInSAR: A methodology based on the integration of SNAP and StaMPS. Geosciences. 9(3), 124. https://doi.org/10.3390/geosciences9030124

3. Chen, Y., Remy, D., Froger, J. L., Peltier, A., Villeneuve, N., Darrozes, J., ... \& Bonvalot, S., 2017. Long-term ground displacement observations using InSAR and GNSS at Piton de la Fournaise volcano between 2009 and 2014. Remote Sensing of Environment. 194, $230-247$.

https://doi.org/10.1016/j.rse.2017.03.038

4. Del Soldato, M., Farolfi, G., Rosi, A., Raspini, F., Casagli, N., 2018. Subsidence evolution of the Firenze-Prato-Pistoia plain (Central Italy) combining PSI and GNSS data. Remote Sensing. 10(7), 1146. https://doi.org/10.3390/rs10071146

5. Dong, S., Samsonov, S., Yin, H., Ye, S., Cao, Y., 2014. Time-series analysis of subsidence associated with rapid urbanization in Shanghai, China measured with SBAS InSAR method. Environmental earth sciences. 72(3), 677-691. https://doi.org/10.1007/s12665-013-2990-y

6. Ferretti, A., Prati, C., Rocca, F., 2001. Permanent scatterers in SAR interferometry. IEEE Trans. Geosci. Remote Sensing. 39, 8-20. https://doi.org/10.1109/36.898661

7. Ferretti, A., Monti-guarnieri, A., Prati, C., Rocca, F., 2007. InSAR Principles: Guidelines for SAR Interferometry Processing and Interpretation (TM-19, February 2007); ESA Publications: Auckland, New Zealand, ISBN 92-9092-233-8. https://doi.org/10.1287/ited.1100.0047

8. Gido, N. A., Bagherbandi, M., Nilfouroushan, F., 2020. Localized subsidence zones in Gävle City detected by Sentinel-1 PSI and Leveling data. Remote Sensing. 12(16), 2629. https://doi.org/10.3390/rs12162629

9. Gu, K., Shi, B., Liu, C., Jiang, H., Li, T., Wu, J., 2018. Investigation of land subsidence with the combination of distributed fiber optic sensing techniques and microstructure analysis of soils. Eng Geol. 240, 34-47. https://doi.org/10.1016/j.enggeo.2018.04.004

10. Goorabi, A., Karimi, M., Yamani, M., \& Perissin, D., 2020. Land subsidence in Isfahan metropolitan and its relationship with geological and geomorphological settings revealed by Sentinel-1A InSAR observations. Journal of Arid Environments. 181, 104238. https://doi.org/10.1016/j.jaridenv.2020.104238

11. Galloway, D. L., Hudnut, K. W., Ingebritsen, S. E., Phillips, S. P., Peltzer, G., Rogez, F., \& Rosen, P. A., 1998. Detection of aquifer system compaction and land subsidence using interferometric synthetic aperture radar, Antelope Valley, Mojave Desert, California. Water Resour Res. 34(10), $2573-2585$. https://doi.org/10.1029/98wr01285

12. Francesca, G., Mancini, F., 2019. Sentinel-1 data for ground deformation monitoring: the SNAP-StaMPS workflow. In $12^{\circ}$ Workshop Tematico di Telerilevamento (pp. 20-25). ITA.

13. Hoffmann, J., Zebker, H. A., Galloway, D. L., Amelung, F., 2001. Seasonal subsidence and rebound in Las Vegas Valley, Nevada, observed by synthetic aperture radar interferometry. Water Resour Res. 37(6), 1551-1566. https://doi.org/10.1029/2000wr900404

14. Hooper, A., 2008. A multi-temporal InSAR method incorporating both persistent scatterer and small baseline approaches. Geophys Res Lett. $35,16302$. https://doi.org/10.1029/2008gl034654

15. Hung, W. C., Hwang, C., Chen, Y. A., Zhang, L., Chen, K. H., Wei, S. H., ... \& Lin, S. H., 2018. Land subsidence in Chiayi, Taiwan, from compaction well, leveling and alos/palsar: Aquaculture-induced relative sea level rise. Remote Sensing. 10(1), 40. https://doi.org/10.3390/rs10010040

16. Khorrami, M., Abrishami, S., Maghsoudi, Y., Alizadeh, B., \& Perissin, D., 2020. Extreme subsidence in a populated city (Mashhad) detected by PSInSAR considering groundwater withdrawal and geotechnical properties. Scientific Reports. 10(1), 1-16. https://doi.org/10.1038/s41598-020-67989-1

17. Luo, Z. J., Ning, D.『Du, J. J., \& Luo, W., 2019. Influence of Building Load and Groundwater Exploitation on Land Subsidence in Shengze, Wujiang (in Chinese). Journal of Jilin University (Earth Science Edition). 49(2), 514-525. https://doi.org/10.13278/j.cnki.jjuese.20180072.

18. Liu, S. P., Shi, B., Gu, K., Zhang, C. C., Yang, J. L., Zhang, S., Yang, P., 2020. Land subsidence monitoring in sinking coastal areas using distributed fiber optic sensing: a case study. Natural Hazards. 103(3), 3043-3061. https://doi.org/10.1007/s11069-020-04118-1

19. Loesch, E., Sagan, V., 2018. SBAS analysis of induced ground surface deformation from wastewater injection in East Central Oklahoma, USA. Remote Sensing. 10(2), 283. https://doi.org/10.3390/rs10020283 
20. Li, H. N., Li, D. S., Song, G. B., 2004. Recent applications of fiber optic sensors to health monitoring in civil engineering. Engineering structures. 26(11), 1647-1657. https://doi.org/10.1016/j.engstruct.2004.05.018

21. Liu, S. P., Shi, B., Gu, K., Zhang, C. C., Zhang, S., Yang, P., Yang, J. L., 2020. Application of distributed fiber optic sensing technique in land subsidence monitoring in coastal areas: a case study in Tianjin, China. Proceedings of the International Association of Hydrological Sciences. 382, $137-141$. https://doi.org/10.5194/piahs-382-137-2020

22. Miller, M. M., Shirzaei, M., 2019. Land subsidence in Houston correlated with flooding from Hurricane Harvey. Remote Sensing of Environment. 225, 368378. https://doi.org/10.1016/j.rse.2019.03.022

23. Osmanoğlu, B., Dixon, T. H., Wdowinski, S., Cabral-Cano, E., Jiang, Y., 2011. Mexico City subsidence observed with persistent scatterer InSAR. International Journal of Applied Earth Observation and Geoinformation. 13(1), 1-12. https://doi.org/10.1016/j.jag.2010.05.009

24. Ohno, H., Naruse, H., Kihara, M., Shimada, A., 2001. Industrial Applications of the BOTDR Optical Fiber Strain Sensor. Opt Fiber Technol. 7, 4564. https://doi.org/10.1006/ofte.2000.0344

25. Phien-Wej, N., Giao, P. H., Nutalaya, P., 2006. Land subsidence in Bangkok, Thailand. Engineering geology. 82(4), $187-201$. https://doi.org/10.1016/j.enggeo.2005.10.004

26. Poland, M., Bürgmann, R., Dzurisin, D., Lisowski, M., Masterlark, T., Owen, S., Fink, J., 2006. Constraints on the mechanism of long-term, steady subsidence at Medicine Lake volcano, northern California, from GPS, leveling, and InSAR. Journal of Volcanology and Geothermal Research. 150(1-3), 5578. https://doi.org/10.1016/j.jvolgeores.2005.07.007

27. Shi, X., Fang, R., Wu, J., Xu, H., Sun, Y., \& Yu, J., 2012. Sustainable development and utilization of groundwater resources considering land subsidence in Suzhou, China. Engineering geology. 124, 77-89. https://doi.org/10.1016/j.enggeo.2011.10.005

28. Shi, G., Ma, P., Hu, X., Huang, B., Lin, H., 2021. Surface response and subsurface features during the restriction of groundwater exploitation in Suzhou (China) inferred from decadal SAR interferometry. Remote Sensing of Environment. 256, 112327. https://doi.org/10.1016/j.rse.2021.112327

29. Sang, H., Zhang, D., Gao, Y., Zhang, L., Wang, G., Shi, B., ... \& Liu, Y., 2019. Strain distribution based geometric models for characterizing the deformation of a sliding zone. Engineering Geology. 263, 105300. https://doi.org/10.1016/j.enggeo.2019.105300

30. Sun, H., Zhang, Q., Zhao, C., Yang, C., Sun, Q., Chen, W., 2017. Monitoring land subsidence in the southern part of the lower Liaohe plain, China with a multi-track PS-InSAR technique. Remote sensing of environment. 188, 73-84. https://doi.org/10.1016/j.rse.2016.10.037

31. Wu, J., Shi, B., Gu, K., Liu, S., Wei, G., 2021. Evaluation of land subsidence potential by linking subsurface deformation to microstructure characteristics in Suzhou, China. Bulletin of Engineering Geology and the Environment. 80(3), 2587-2600. https://doi.org/10.1007/s10064-020-02056-7

32. Wang, L., Deng, K., Zheng, M., 2020., Research on ground deformation monitoring method in mining areas using the probability integral model fusion DInSAR, sub-band InSAR and offset-tracking. International Journal of Applied Earth Observation and Geoinformation. 85, 101981. https://doi.org/10.1016/j.jag.2019.101981

33. Wu, J., Jiang, H., Su, J., Shi, B., Jiang, Y., Gu, K., 2015. Application of distributed fiber optic sensing technique in land subsidence monitoring. Journal of Civil Structural Health Monitoring. 5(5), 587-597. https://doi.org/10.1007/s13349-015-0133-8

34. Wu, J., Shi, X., Xue, Y., Zhang, Y., Wei, Z., Yu, J., 2008. The development and control of the land subsidence in the Yangtze Delta, China. Environ Geol. 55(8), 1725-1735. https://doi.org/10.1007/s00254-007-1123-x

35. Xiao, R., He, X., He, M., 2011. PS InSAR processing methodologies in the detection of ground surface deformation: a case study of Nantong City. In International Symposium on Lidar and Radar Mapping 2011: Technologies and Applications (Vol. 8286, p. 82860L). International Society for Optics and Photonics. https://doi.org/10.1117/12.912522

36. Yu, H., Gong, H., Chen, B., Liu, K., Gao, M., 2020. Analysis of the influence of groundwater on land subsidence in Beijing based on the geographical weighted regression (GWR) model. Science of The Total Environment. 738, 139405. https://doi.org/10.1016/j.scitotenv.2020.139405

37. Yan, Y., Doin, M. P., López-Quiroz, P., Tupin, F., Fruneau, B., Pinel, V., \& Trouvé, E., 2012. Mexico City subsidence measured by InSAR time series: Joint analysis using PS and SBAS approaches. IEEE Journal of Selected Topics in Applied Earth Observations and Remote Sensing. 5(4), $1312-1326$. https://doi.org/10.1109/JSTARS.2012.2191146

38. Zhang, Y., Zhang, J., Wu, H., Lu, Z., Guangtong, S., 2011. Monitoring of urban subsidence with SAR interferometric point target analysis: A case study in Suzhou, China. International Journal of Applied Earth Observation and Geoinformation. 13(5), 812-818. https://doi.org/10.1016/j.jag.2011.05.003

39. Zhu, H. H., Shi, B., Yan, J. F., Zhang, J., Zhang, C. C., Wang, B. J., 2014. Fiber Bragg grating-based performance monitoring of a slope model subjected to seepage. Smart Materials and Structures. 23(9), 095027. https://doi.org/10.1088/0964-1726/23/9/095027

40. Zhang, C. C., Shi, B., Gu, K., Liu, S. P., Wu, J. H., Zhang, S., ... \& Wei, G. Q., et al 2018. Vertically distributed sensing of deformation using fiber optic sensing. Geophysical Research Letters. 45(21), 732-741. https://doi.org/10.1029/2018GL080428

\section{Figures}




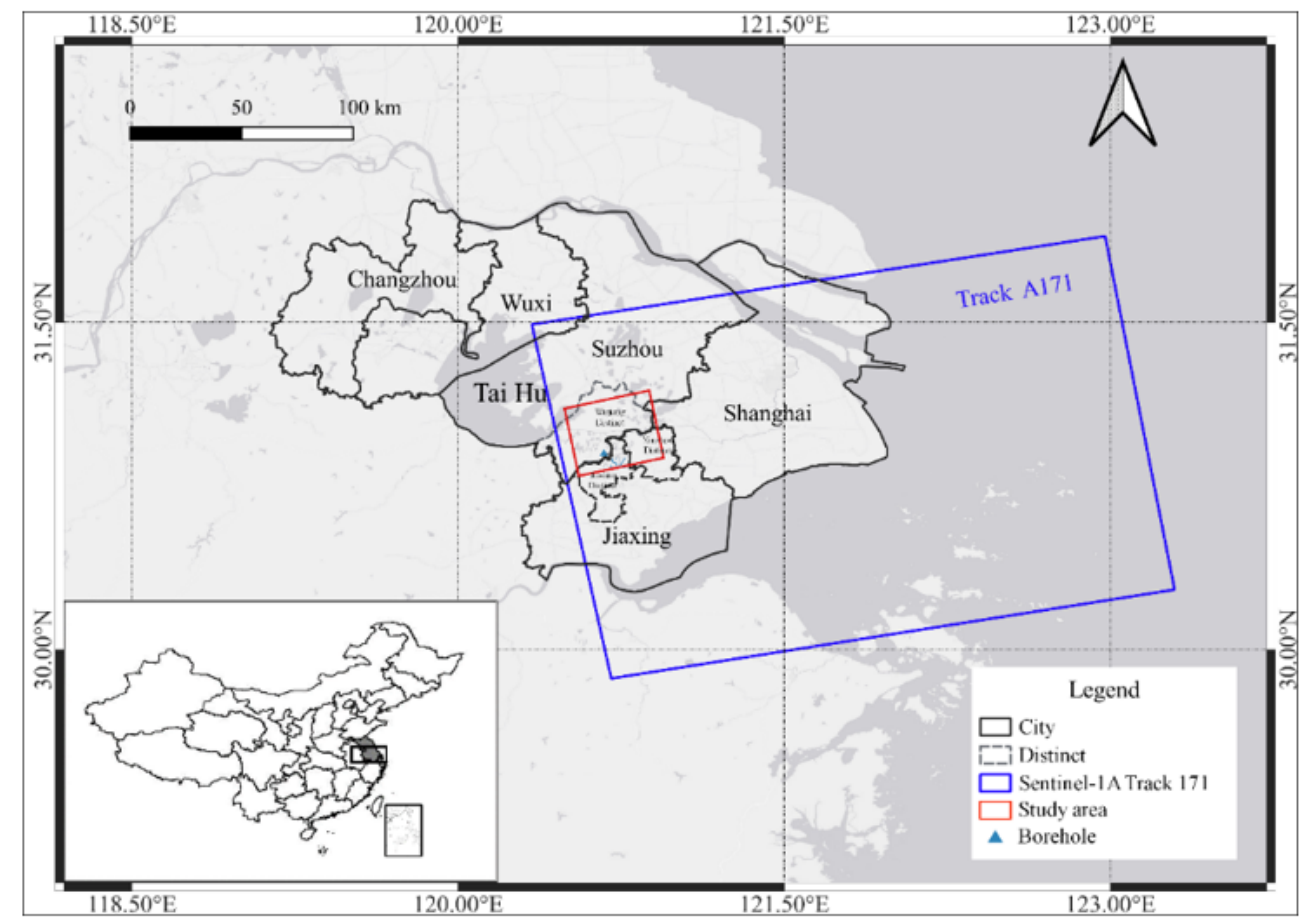

\section{Figure 1}

The overview of the study area.

\begin{tabular}{|c|c|c|c|c|c|}
\hline \multicolumn{2}{|c|}{ Chronostratigraphic } & $\begin{array}{l}\text { Aquifer } \\
\text { groups }\end{array}$ & Depth & $\begin{array}{c}\text { Lithoiogical } \\
\text { column }\end{array}$ & Lithology \\
\hline $\begin{array}{c}\text { Holacene } \\
\text { Series } \\
\text { Sello }\end{array}$ & Qh & & $\frac{2}{53}$ & $\therefore \quad \therefore$ & $\begin{array}{l}\text { 0.2m Filling. } \\
\text { 2-5.3m Green gray muddy clay. }\end{array}$ \\
\hline \multirow{10}{*}{ 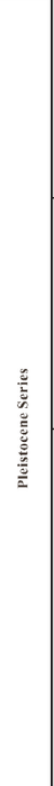 } & \multirow[t]{2}{*}{ Qp 3} & Ad1 1 & \begin{tabular}{|l|}
19.8 \\
24.55 \\
25.95 \\
31.53 \\
\end{tabular} & 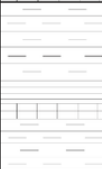 & 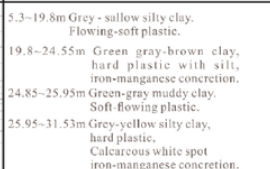 \\
\hline & & Aft & 41,2 & $\because \because . .$. & 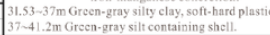 \\
\hline & \multirow[t]{2}{*}{ Qp2 } & Ad 2 & $\begin{array}{r}50.9 \\
57.2 \\
68.5 \\
74.35 \\
\end{array}$ & 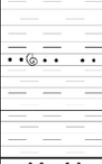 & 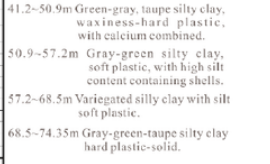 \\
\hline & & A12 & & $\because \because \because \because$ & 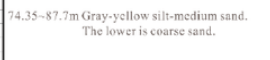 \\
\hline & \multirow{6}{*}{ Qp1 } & \multirow{5}{*}{${ }_{A d 3}$} & 97.1 & & 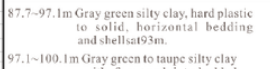 \\
\hline & & & & $\because \cdots$ & 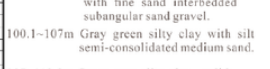 \\
\hline & & & 1113.2 & $\Delta$ & 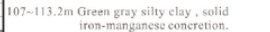 \\
\hline & & & 124.5 & & 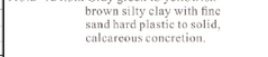 \\
\hline & & & 137.9 &... & 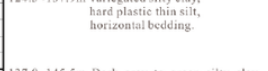 \\
\hline & & $A / 3$ & 145.8 & $\therefore \therefore$ & 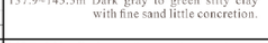 \\
\hline & \multirow[b]{2}{*}{$\mathrm{N}_{2}$} & & & $\therefore \because$ & 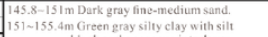 \\
\hline & & $\mathrm{Ad} 4$ & $\begin{array}{l}155.4 \\
158.3 \\
160.3 \\
105.1\end{array}$ & $\because \vdots \vdots \vdots \vdots$ & 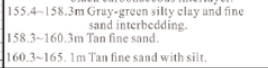 \\
\hline 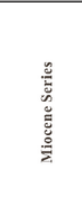 & $\mathrm{N} 1$ & s.s & $\begin{array}{l}169.5 \\
172.7 \\
180 \\
180 \\
185.1 \\
186.5 \\
1189.7 \\
193.5 \\
198.1 \\
200\end{array}$ & 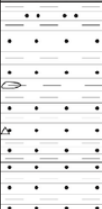 & 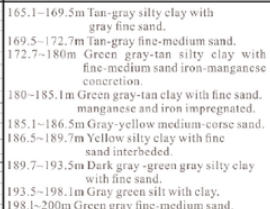 \\
\hline
\end{tabular}

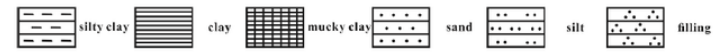

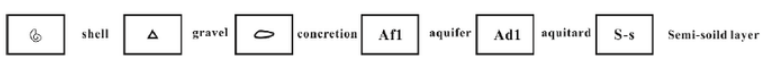

Figure 2 
Detailed lithology and aquifer system classification in Shengze borehole (modified from Wu et al. 2021).
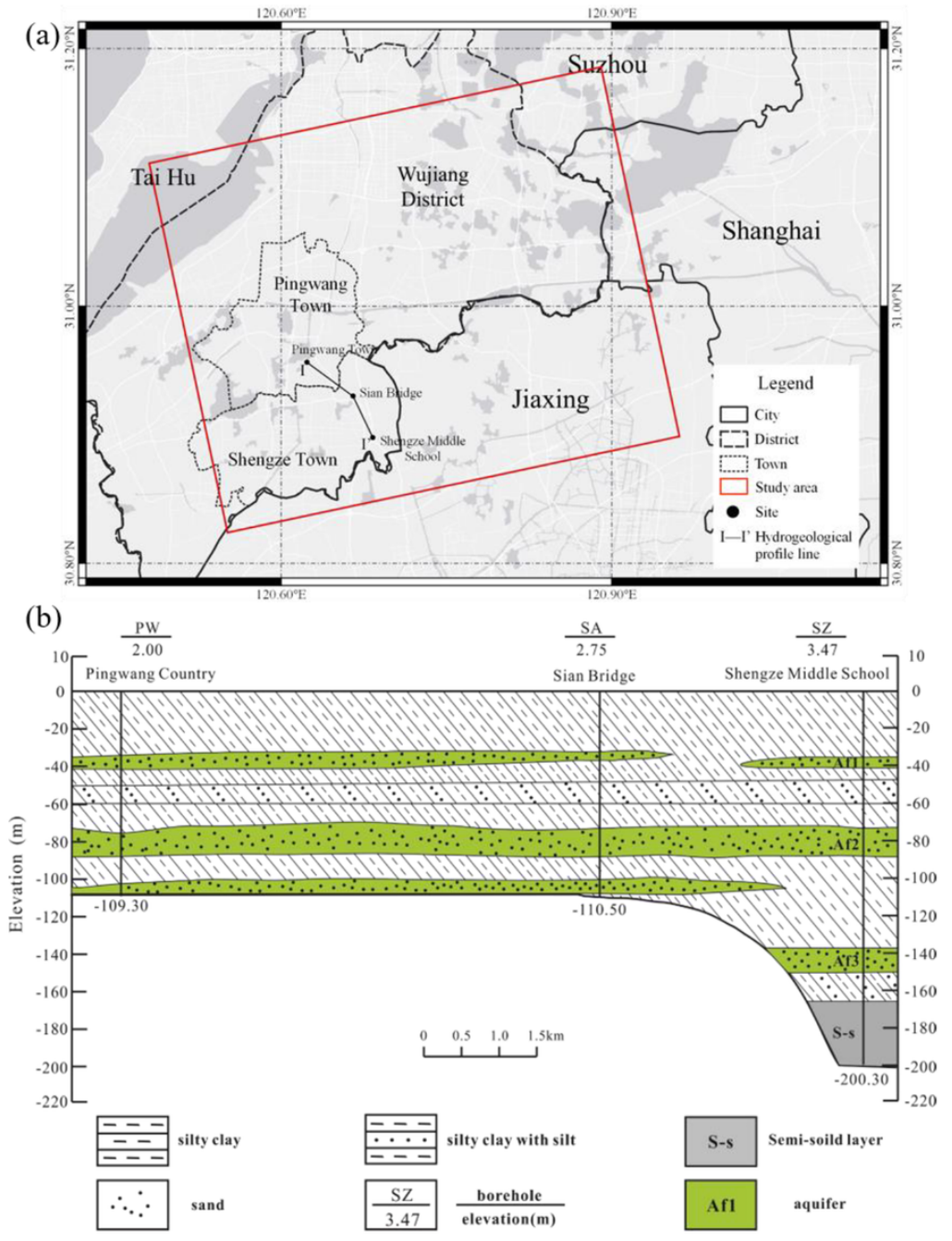

\section{Figure 3}

(a) Detailed map of the study area; (b) The hydrogeological profile of the study area along the $\mathbb{\|} \mathbb{Z}^{\prime}$ direction (modified from Luo et al. 2019). 


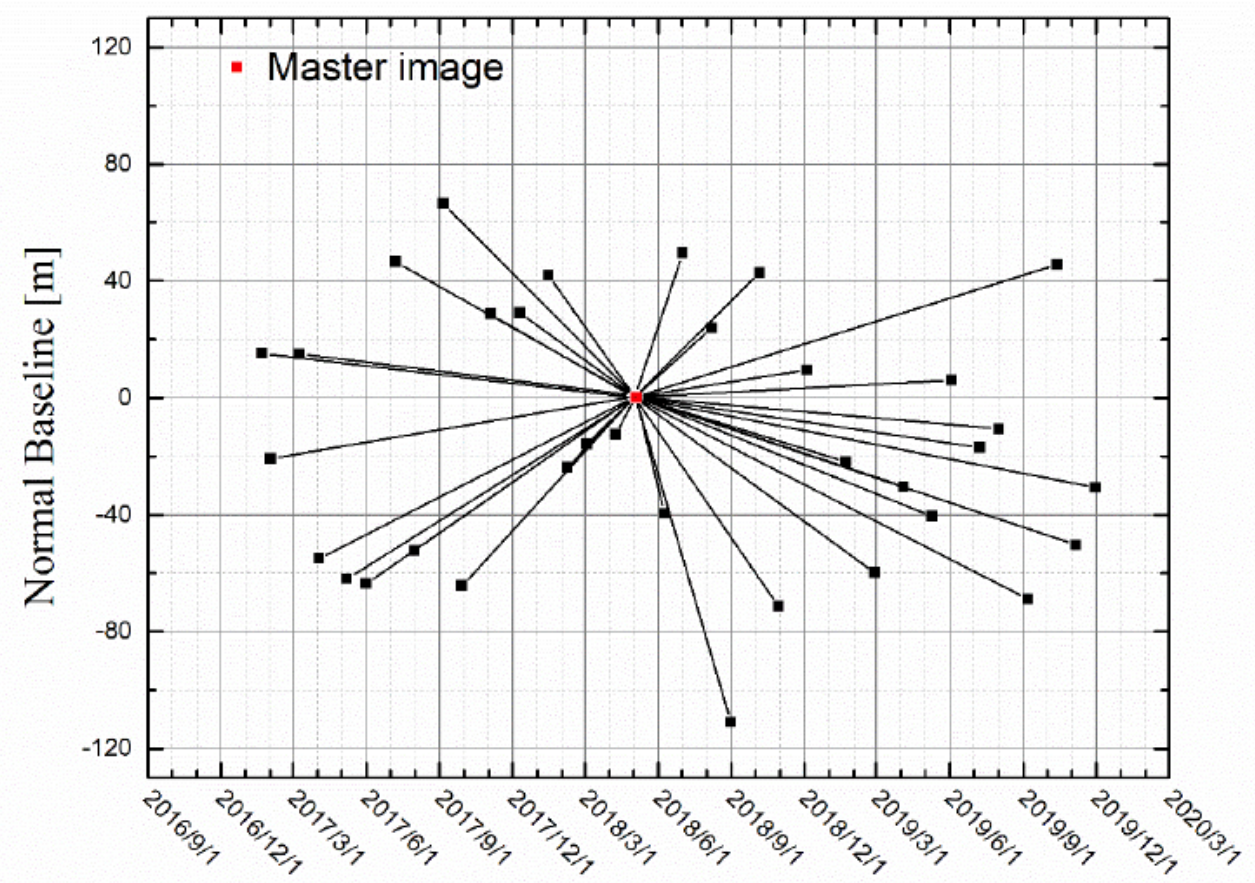

Date

\section{Figure 4}

The spatial and temporal baseline configuration of Sentinel-1A (Track 171) interferometric pairs.

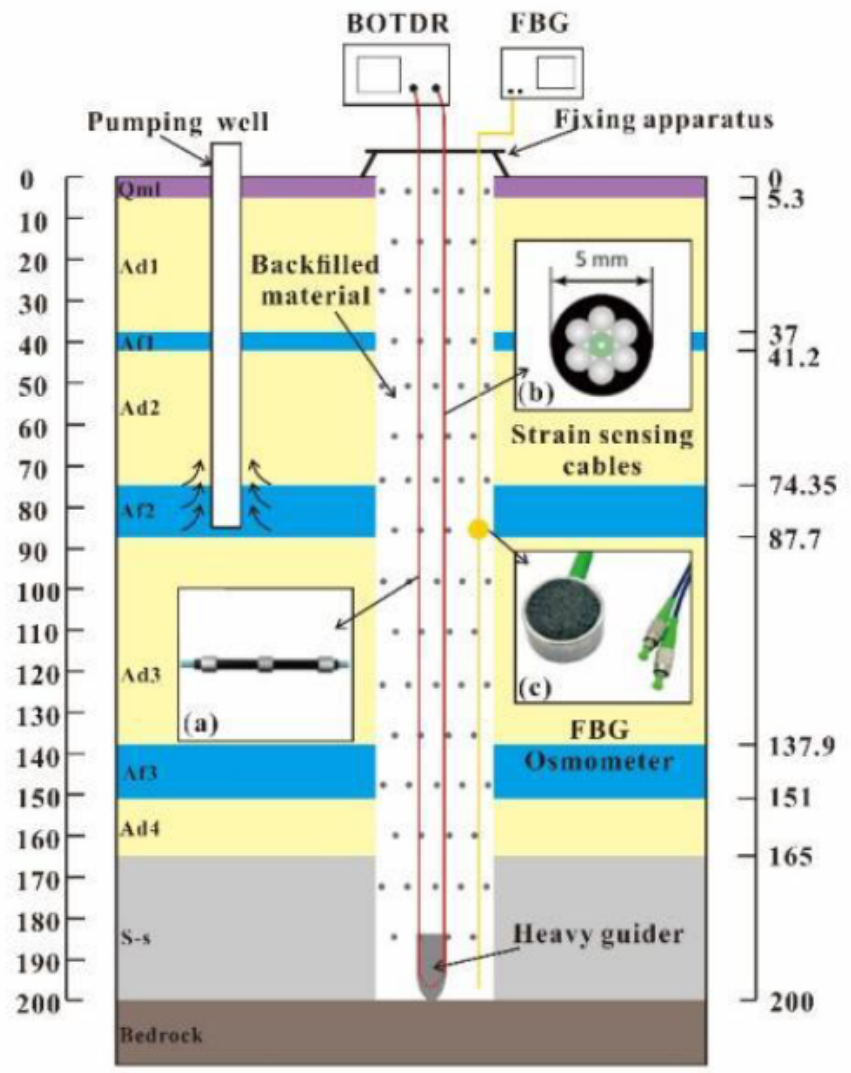


Land subsidence monitoring using DFOS in borehole SZ. (a) 10-m-fixed-point cable; (b) The cross-section of the strain sensing cable; (c) The FBG osmometer. 政

Figure 6

Subsidence rate in LOS direction between 2017 and 2019 measured in mm/year. The dot black line represents the subsidence rate change cross-sections as (i) Cross-section for I-I' line North-South.
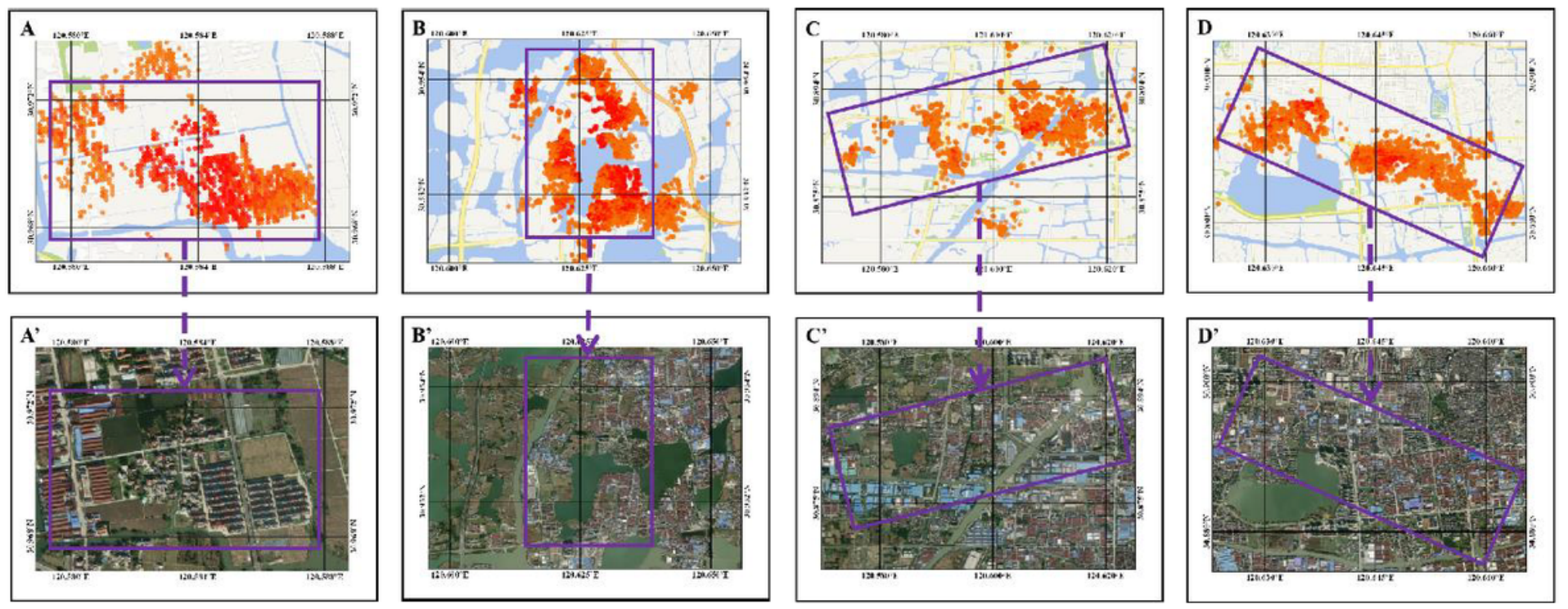

Figure 7

The spatial distribution characteristics of the subsidence area $A, B, C$, and D.
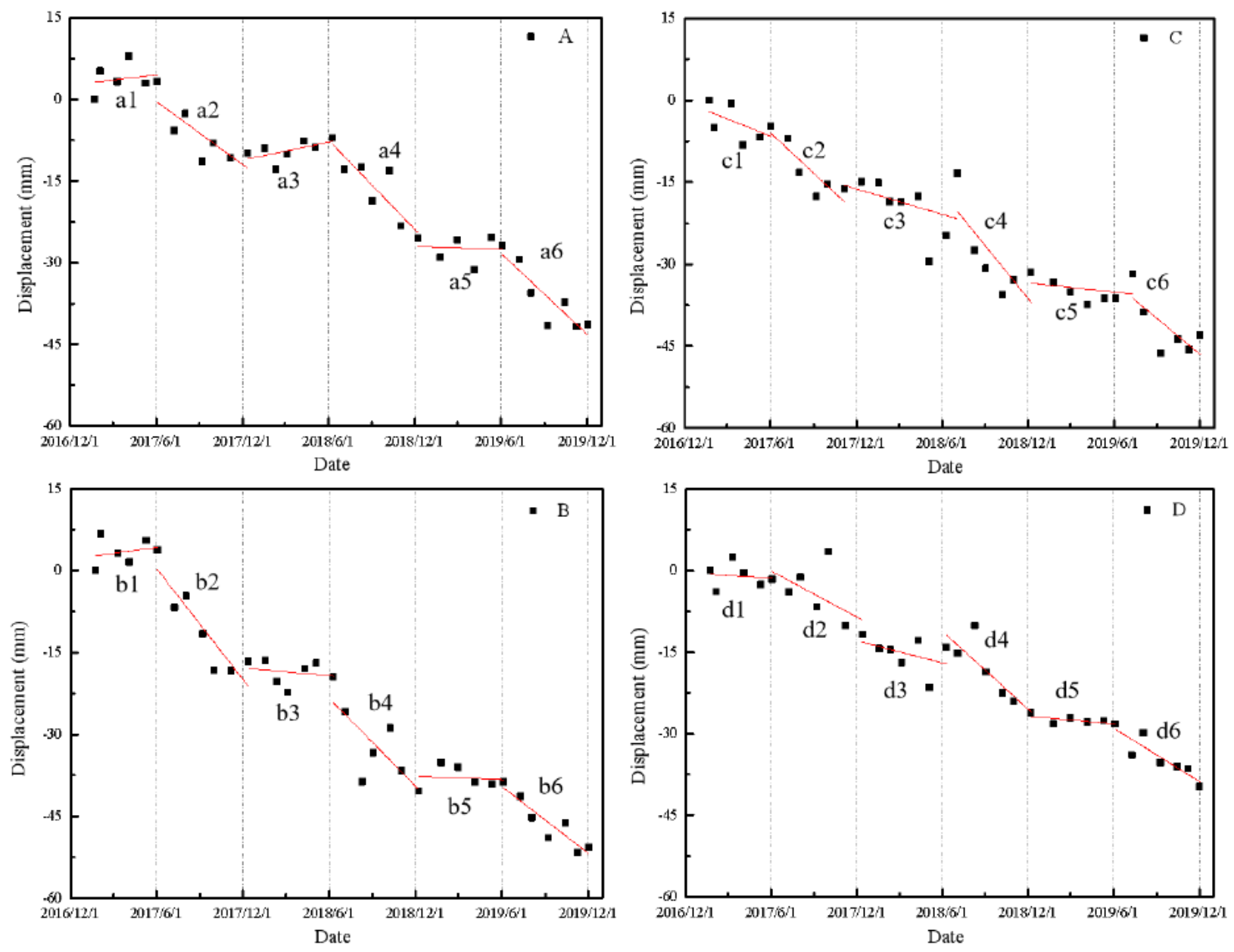
Figure 8

The time series of average LOS displacements within $100 \mathrm{~m}$ radius near the center of the A, B, C, and D areas.

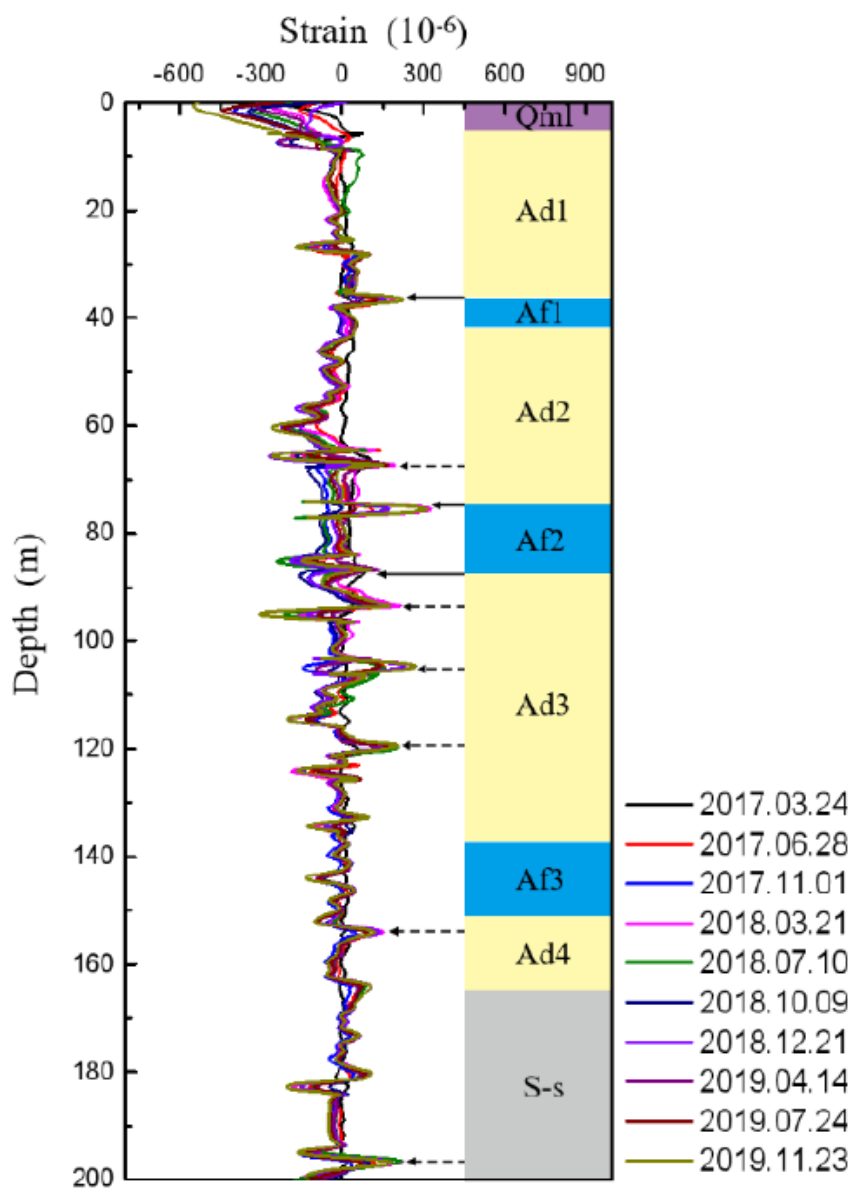

Figure 9

The monitored strain profiles in the borehole SZ after processing.

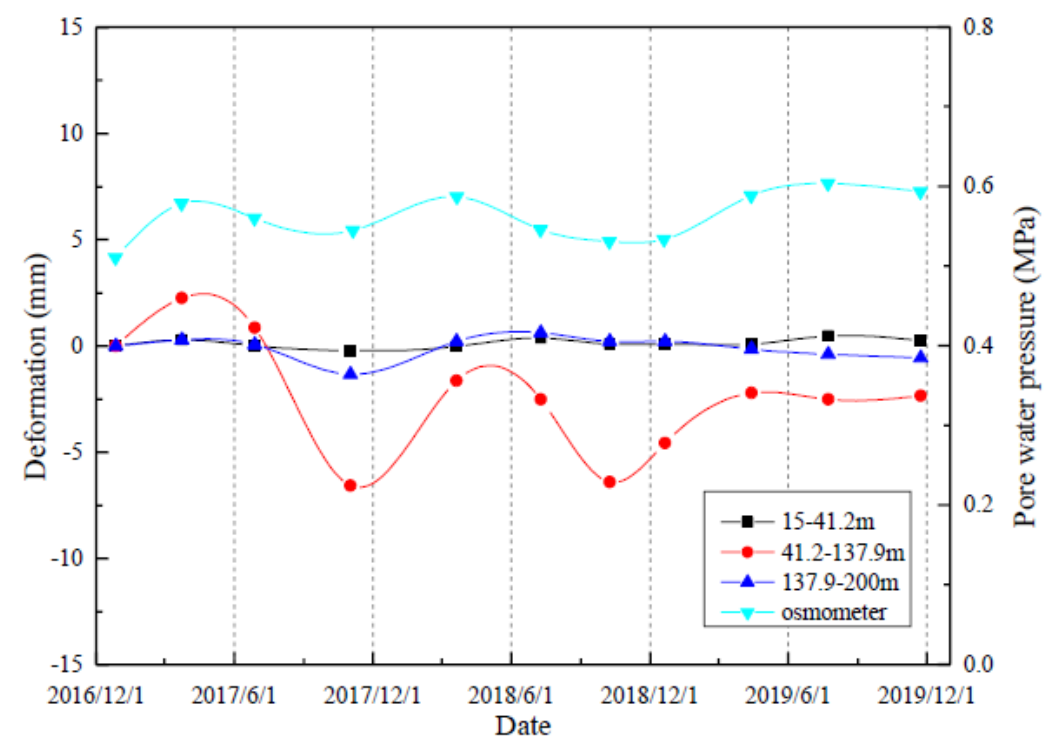

Figure 10

The deformation in the different depth ranges (from 15 to $200 \mathrm{~m}$ depth) along the borehole SZ and the variation of the pore water pressure in Af2. 


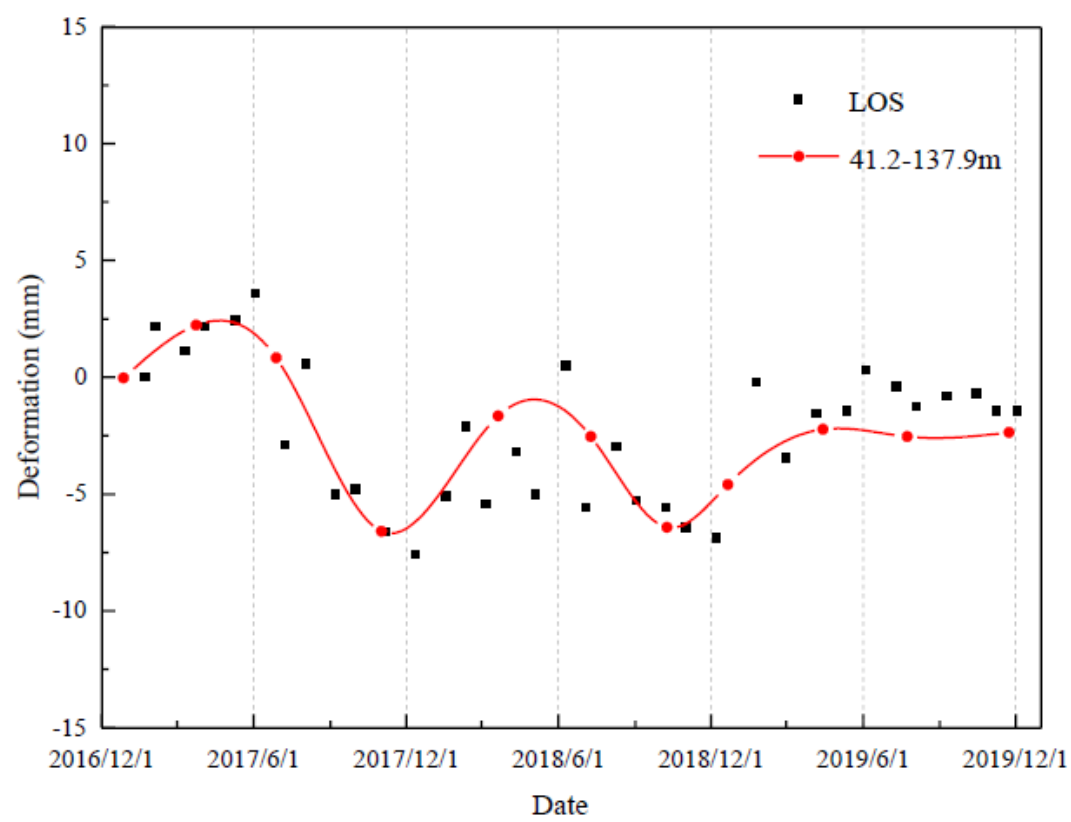

Figure 11

The comparison between the average LOS displacements within $100 \mathrm{~m}$ radius near the center of the borehole SZ and the deformation on 41.2 to $137.9 \mathrm{~m}$ depth obtained by the DFOS technique.

(a)

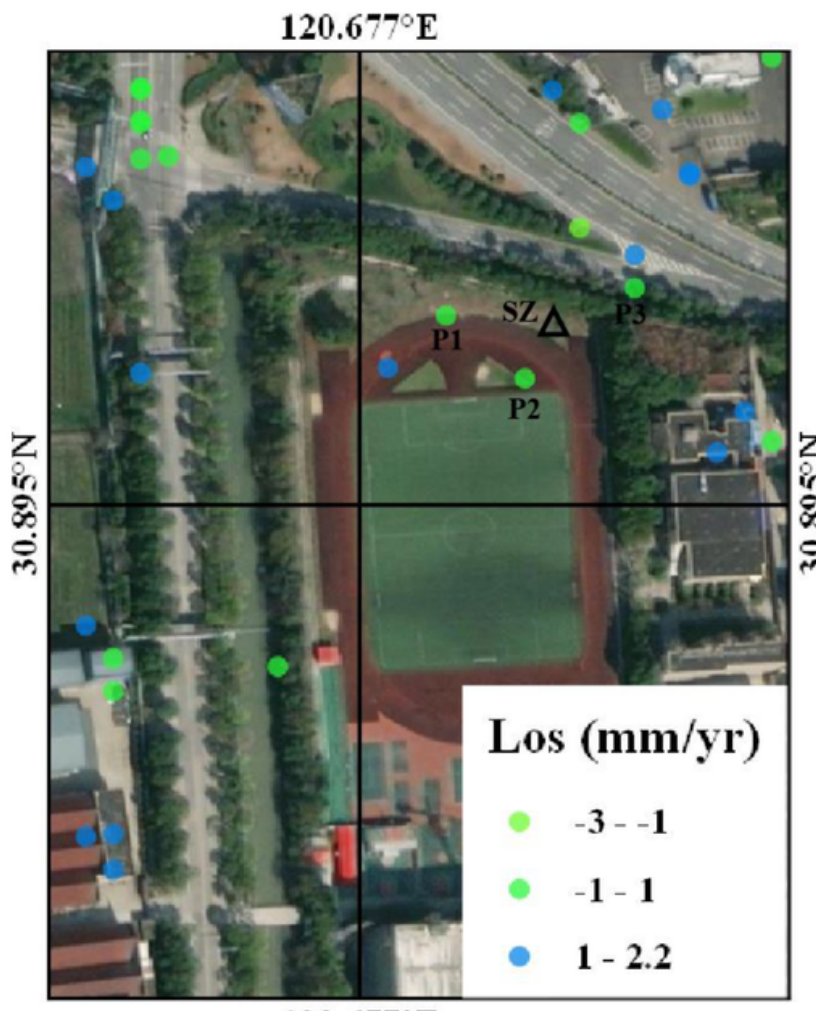

$120.677^{\circ} \mathrm{E}$ (b)
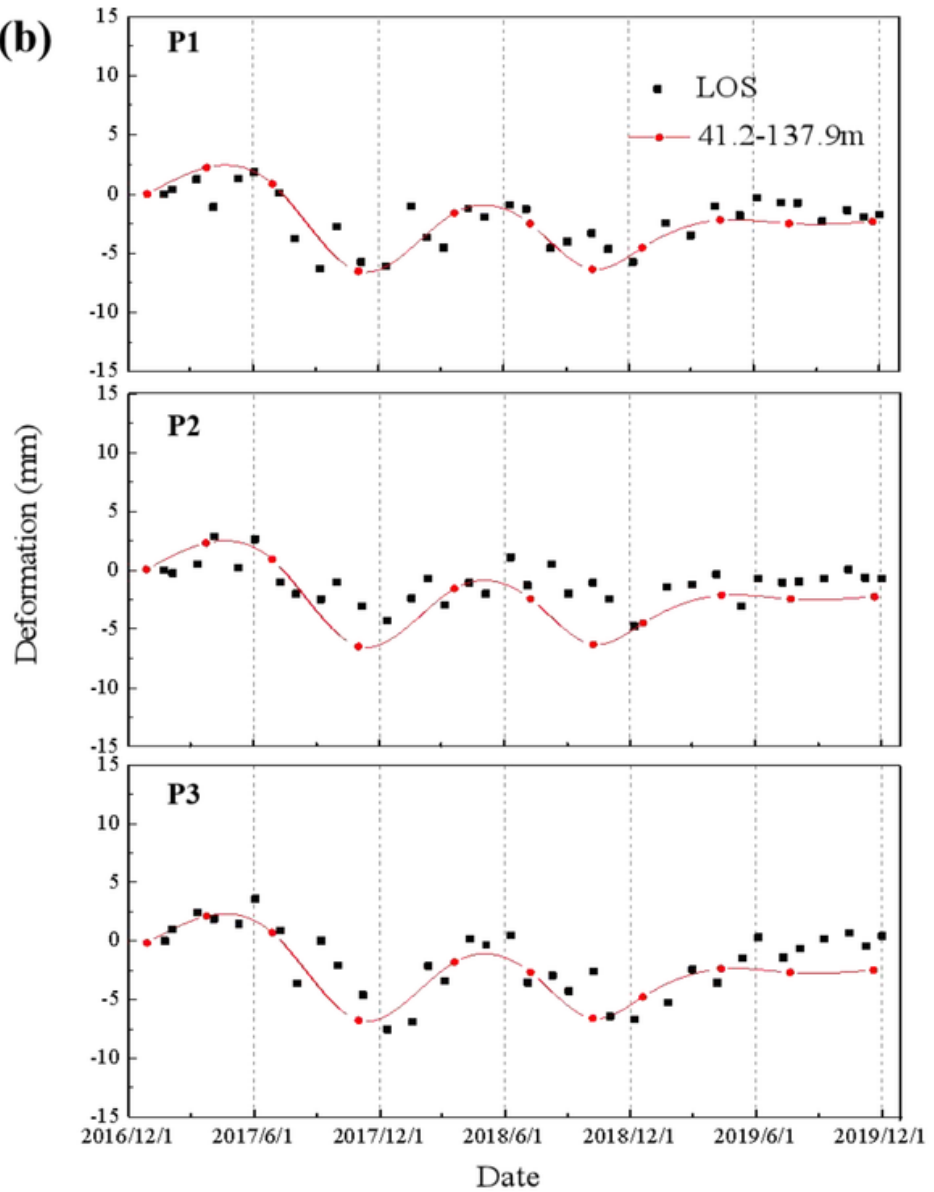

Figure 12 
(a) The distribution of the deformation rate obtained by the PSI near the borehole SZ; (b) The time series of the LOS deformation turned in P1, P2, and P3 near the borehole SZ.

Page $15 / 15$ 